\title{
Acceptance of animal research in our science community
}

\section{[version 1; peer review: 3 approved]}

\section{Konstantin Bergmeister ${ }^{1,2}$, Bruno Podesser ${ }^{2}$}

${ }^{1}$ CD Laboratory for the Restoration of Extremity Function, Department of Surgery, Medical University of Vienna, Vienna, Austria

${ }^{2}$ Department of Biomedical Research, Medical University of Vienna, Vienna, Austria

V1 First published: 04 Mar 2016, 5:282

https://doi.org/10.12688/f1000research.8169.1

Latest published: 08 Jul 2016, 5:282

https://doi.org/10.12688/f1000research.8169.2

\section{Abstract}

Animal research is debated highly controversial, as evident by the "Stop Vivi-section" initiative in 2015. Despite widespread protest to the initiative by researchers, no data is available on the European medical research community's opinion towards animal research. In this singlecenter study, we investigated this question in a survey of students and staff members at the Medical University of Vienna. A total of 906 participants responded to the survey, of which $82.8 \%$ rated the relevance of animal research high and $62 \%$ would not accept a treatment without prior animals testing. Overall, animal research was considered important, but its communication to the public considered requiring improvement.

\section{Keywords}

Animal research, survey, acceptance animal research , Stop vivisection,

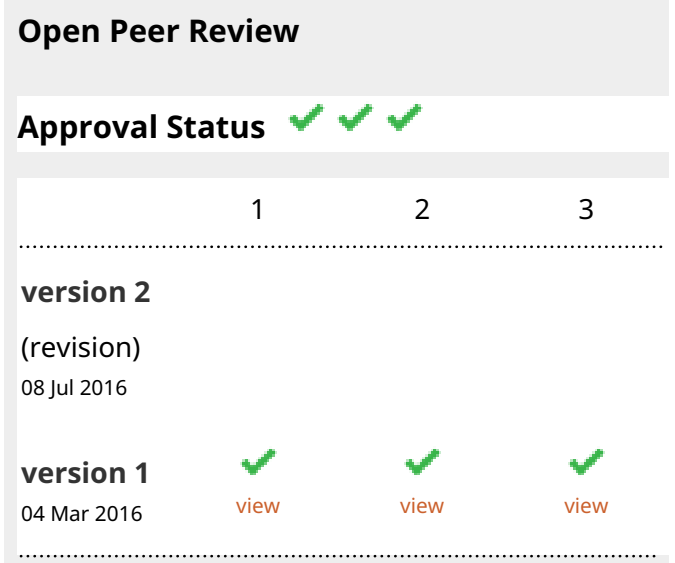

1. Thomas Butts, University of Liverpool, Liverpool, UK

2. David B. Lumenta, Medical University of Graz, Graz, Austria

\section{David Bernhard, Medical University of} Innsbruck, Innsbruck, Austria

Any reports and responses or comments on the article can be found at the end of the article.

Corresponding author: Bruno Podesser (bruno.podesser@meduniwien.ac.at)

Competing interests: No competing interests were disclosed.

Grant information: This work was supported by the Christian Doppler Research Association.

The funders had no role in study design, data collection and analysis, decision to publish, or preparation of the manuscript.

Copyright: ( 2016 Bergmeister K and Podesser B. This is an open access article distributed under the terms of the Creative Commons Attribution License, which permits unrestricted use, distribution, and reproduction in any medium, provided the original work is properly cited. Data associated with the article are available under the terms of the Creative Commons Zero "No rights reserved" data waiver (CC0 1.0 Public domain dedication).

How to cite this article: Bergmeister $\mathrm{K}$ and Podesser $\mathrm{B}$. Acceptance of animal research in our science community [version 1; peer review: 3 approved] F1000Research 2016, 5:282 https://doi.org/10.12688/f1000research.8169.1

First published: 04 Mar 2016, 5:282 https://doi.org/10.12688/f1000research.8169.1 


\section{Introduction}

Animal research is still debated highly controversial and lately attracted great attention as over 1.1 million European citizens signed the "Stop Vivi-section" initiative in 2015, demanding the stop of all animal research ${ }^{1}$. Alarmed by the potential consequences opinion leaders made efforts to illustrate the need for animal experiments for medical progress ${ }^{2,3}$. However, does the European medical research community stand united behind animal research?

\section{Methods}

In an internal survey at the Medical University of Vienna we investigated the positions towards animal research of 10335 (M.D. and Ph.D.) students and 3824 medical staff members. The survey was conducted using the MedCampus system (CAMPUSOnline, Graz, Austria) of the Medical University of Vienna, accessible to all students and staff members. The survey was conducted over a period of four weeks in November 2015. Statistical analyses were conducted using SPSS (V.21, IBM Corp, US).

Ethics committee approval: Approval was obtained from the Medical University of Vienna's data privacy committee.

\section{Results}

Dataset 1. Word file containing survey questions in original German language and translated to English

http://dx.doi.org/10.5256/f1000research.8169.d115219

Dataset 2. Excel file containing anonymized responses to the survey

http://dx.doi.org/10.5256/f1000research.8169.d115220
A total of 906 participants responded to the survey, resulting in a response rate of $6.38 \%$. Participants were $36.5 \%$ staff members and $63.5 \%$ students, of which $43 \%$ previously had personal experience with animal experiments. The relevance of animal models for research was rated high (8-10 on a scale $1-10$; 1 being lowest) by $82.8 \%$, and $62 \%$ would not accept a treatment without prior animals testing (Figure 1, left). These results were similar to a 2011 Nature poll ${ }^{4}$ with 980 participants and a 2014 survey by the American Association for the Advancement of Sciences ${ }^{5}$. In our cohort, participants rated the society's acceptance of animal research low $(4.24 \pm 1.77$, scale $1-10 ; 1$ being lowest) as well as the current communication to the public on medical advances derived from animal research $(4.37 \pm 2.22$, scale $1-10 ; 1$ being lowest). Consequently, $75.4 \%$ believed the public should receive better information about the benefits, necessities and legislation of animal experiments (Figure 1, right).

\section{Discussion}

In this study, we assessed the opinions of our faculty members and students towards animal research. Overall, our study population considered animal research important for medical progress. In addition, we see a clear mission to improve communication to the public about animal experiments. Moreover, scientists need to improve the communication of complex results into a language that is understood by society and colleagues alike. Limitations of this study were the small number of participants and being a singlecenter survey. A comparable nature study ${ }^{4}$ from 2011 had a relatively lower response rate (approximately 4.9\%) and a similar total number of 980 participants.

In conclusion, this single-center study provides first survey results of students and medical faculty members towards animal research. Based on the interesting results, we plan to extend this study to other institutions and thereby provide an overview of the European medical community's opinion towards animal research.

\section{Treatment without prior animal testing ?}

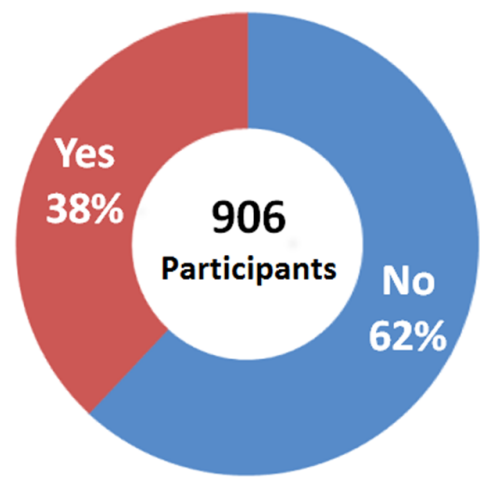

\section{Better information about animal research for the public?}

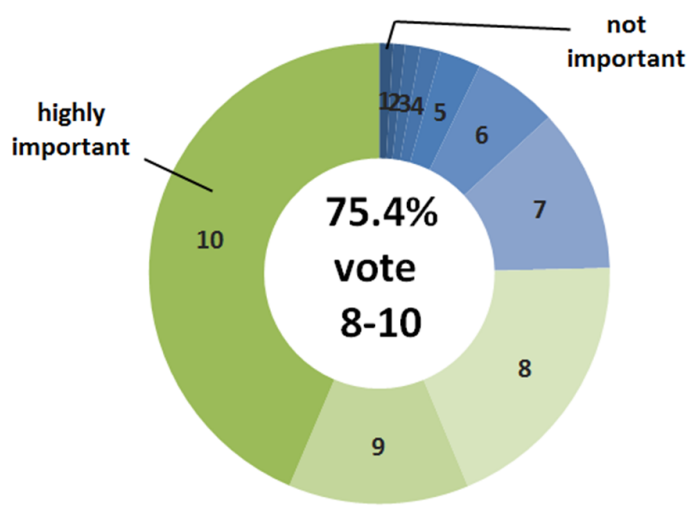

Figure 1. Survey results. Left: A majority of participants would not accept a treatment that has not been previously tested in animal models. Right: The need for better information about animal research for the public was rated high by $75 \%$ of the participants. 


\section{Data availability}

F1000Research: Dataset 1. Word file containing survey questions in original German language and translated to English, 10.5256/ f1000research.8169.d115219

F1000Research: Dataset 2. Excel file containing anonymized responses to the survey, 10.5256/f1000research.8169.d1152207

Author contributions

$\mathrm{KB}$ and BP both designed the study, and collected, analysed and interpreted the data. $\mathrm{KB}$ carried out the literature search and wrote the manuscript and prepared the figures, while BP revised the manuscript critically.

Competing interests

No competing interests were disclosed.

Grant information

This work was supported by the Christian Doppler Research Association.

I confirm that the funders had no role in study design, data collection and analysis, decision to publish, or preparation of the manuscript.
1. Balls M: The European Citizens' Stop Vivisection Initiative. Altern Lab Anim. 2015; 43(3): 147-50.

PubMed Abstract

2. Mohdin A: The Stop Vivisection Initiative - Trying to Ban European Anima Research. 2015.

Reference Source

3. EARA: Statement supporting European Directive 2010/63/EU ("Directive") on the protection of animals used for scientific purposes. 2016.

Reference Source
4. Cressey D: Animal research: Battle scars. Nature. 2011; 470(7335): 452-3. PubMed Abstract | Publisher Full Text

5. Funk C, Rainie L, Page D: Public and Scientists'Views on Science and Society. 2015 Reference Source

6. Bergmeister K, Podesser B: Dataset 1 in: Acceptance of animal research in our science community. F1000Research. 2016.

Data Source

7. Bergmeister K, Podesser B: Dataset $\mathbf{2}$ in: Acceptance of animal research in our science community. F1000Research. 2016.

Data Source 


\section{Open Peer Review}

\section{Current Peer Review Status:}

\section{Version 1}

Reviewer Report 10 June 2016

https://doi.org/10.5256/f1000research.8786.r14281

(c) 2016 Bernhard D. This is an open access peer review report distributed under the terms of the Creative Commons Attribution License, which permits unrestricted use, distribution, and reproduction in any medium, provided the original work is properly cited.

\section{David Bernhard}

Cardiac Surgery Research Laboratory, Department of Cardiac Surgery, Medical University of Innsbruck, Innsbruck, Austria

The study is well performed and of high interest for the scientific community. Similar studies in the general population would be very valuable and could help in the discussion and communication of the need for animal experiments.

Competing Interests: No competing interests were disclosed.

I confirm that I have read this submission and believe that I have an appropriate level of expertise to confirm that it is of an acceptable scientific standard.

Reviewer Report 11 May 2016

\section{https://doi.org/10.5256/f1000research.8786.r13710}

(C) 2016 Lumenta D. This is an open access peer review report distributed under the terms of the Creative Commons Attribution License, which permits unrestricted use, distribution, and reproduction in any medium, provided the original work is properly cited.

\section{David B. Lumenta}

Division of Plastic, Aesthetic and Reconstructive Surgery, Department of Surgery, Medical University of Graz, Graz, Austria

Survey among doctoral students and staff members (1 university) on their own and general public's perception of animal experiments with $6.38 \%$ response rate. The presented questionnaire was general without requiring too much detail from respondents, which I found sufficient.

The results are similar to previous research (as cited by the authors), the used methodology 
sound, and the conclusions, notably the need for a more systematic review among institutions in Europe on this topic, well balanced.

Competing Interests: No competing interests were disclosed.

\section{I confirm that I have read this submission and believe that I have an appropriate level of} expertise to confirm that it is of an acceptable scientific standard.

Reviewer Report 26 April 2016

https://doi.org/10.5256/f1000research.8786.r13344

(C) 2016 Butts T. This is an open access peer review report distributed under the terms of the Creative Commons Attribution License, which permits unrestricted use, distribution, and reproduction in any medium, provided the original work is properly cited.

\section{Thomas Butts}

School of Life Science, University of Liverpool, Liverpool, UK

\section{General comments}

This report communicates the details of a small, but not insignificant survey of doctoral students' and professional scientists' from the Medical University of Vienna attitudes towards animal research. The findings, perhaps not surprisingly, reveal strong support for animal research within the life science research community at this single institution, but importantly also highlight an awareness of the short-comings of communicating this necessity to the public in the light of recent political movements in opposition to research using animals. The data in reference to the use of a given medical treatment without previous testing on animals is particularly interesting and will contribute much to the debate. My sole concern with this research is the generality of the questions. For example, a distinction ought to be made in reference to the type and severity of treatment in the survey. Nevertheless, the data presented will contribute to public (and scientific) debate.

The authors are correct in identifying the need for a more systematic survey amongst European life science institutions and professional groups that will inform this important area of public debate.

\section{Specific comments}

\section{Introduction}

Line 1: "...still debated highly controversial and lately..." should read "...still debated, highly controversial, and lately has attracted..."

\section{Methods}


Paragraph 2, line 1: "resulting" should be changed to "representing"

Line 10: "the" should be deleted

Competing Interests: No competing interests were disclosed.

I confirm that I have read this submission and believe that I have an appropriate level of expertise to confirm that it is of an acceptable scientific standard.

The benefits of publishing with F1000Research:

- Your article is published within days, with no editorial bias

- You can publish traditional articles, null/negative results, case reports, data notes and more

- The peer review process is transparent and collaborative

- Your article is indexed in PubMed after passing peer review

- Dedicated customer support at every stage

For pre-submission enquiries, contact research@f1000.com 